\title{
INTERFACES SOCIOESTATAIS E INSTITUIÇÕES PARTICIPATIVAS: DIMENSÕES ANALÍTICAS
}

\author{
Lígia Helena Hahn Lüchmann \\ Professora do Departamento de Sociologia e Ciência Política Universidade Federal \\ de Santa Catarina (UFSC) Florianópolis, SC,Brasil.E-mail: ligia@cfh.ufsc.br \\ Orcid: 0000-0003-2622-2106 \\ http://dx.doi.org/10.1590/0102-013049/109
}

\section{Introdução ${ }^{1}$}

Tanto no âmbito nacional como internacional as últimas décadas foram marcadas pela expansão e multiplicação de modalidades de participação política, em especial aquelas modalidades relacionadas ao envolvimento da população em programas e/ou políticas governamentais. Analisando o cenário internacional com o intuito de refletir sobre os desafios democráticos dessas práticas, Fung (2015) ressaltou três dimensões dessa expansão substancial de inovações participativas, quais sejam: a expansão mundial de determinados modelos, a exemplo do orçamento participativo; ${ }^{2}$ a expansão das áreas, ou temas, abordados no âmbito das modalidades participativas; ${ }^{3}$ e a pluralização e multiplicação

\footnotetext{
1 Este trabalho é resultado do projeto de pesquisa intitulado "Interfaces socioestatais: da participação à burocracia estatal", financiado pelo Conselho Nacional de Desenvolvimento Científico e Tecnológico (CNPq) a partir de uma bolsa de Produtividade em Pesquisa (PQ).

2 Sobre a expansão internacional do OP, ver Sintomer, Herzberg e Röcke (2012).

3 A exemplo de temas constitucionais, como mudanças nas regras eleitorais.
} 
dos atores e instituições que promovem e suportam programas e mecanismos de inovação participativa, em diferentes países ou contextos subnacionais. ${ }^{4}$

No contexto brasileiro, levando em conta os retrocessos derivados do giro conservador no quadro político do país, que vem aprofundando um processo de esvaziamento e de extinção das Instituições Participativas (IP), ${ }^{5}$ é fato que as mesmas têm ocupado um lugar de destaque nos estudos sobre as inovações participativas, como atestado pelo acúmulo de pesquisas sobre as modalidades de IP mais conhecidas: os Conselhos Gestores, os Orçamentos Participativos e as Conferências de Políticas Públicas. Alguns balanços são exemplares no registro desse acúmulo, seja no plano da produção bibliográfica, seja no tocante ao mapeamento dos casos empíricos. Para o primeiro caso, registra-se como exemplo o trabalho de Almeida, Cayres e Tatagiba (2015), que apresenta um mapa da produção acadêmica nacional sobre os Conselhos de Políticas Públicas entre os anos de 2000 a 2011. Neste estudo, as autoras encontraram 537 trabalhos produzidos, somando-se teses, dissertações e artigos. Para o segundo caso, o registro vai para o estudo desenvolvido por Lopez e Pires (2010), que apresenta um panorama das IP no país, destacando as principais modalidades encontradas na esfera federal; de acordo com os autores, entre os anos de 1988 e 2009 foram realizadas 80 conferências nacionais, em diferentes áreas de políticas públicas. No que diz respeito aos conselhos, foram identificados 31 conselhos nacionais no período, mobilizando mais de mil conselheiros (incluindo-se os representantes do governo e da sociedade civil),

\footnotetext{
4 Com destaque às várias iniciativas provenientes do campo legislativo e judiciário, para além do protagonismo das agências e/ou setores do poder executivo.

5 Uma das primeiras medidas do novo governo que venceu as eleições de 2018 no país foi a edição do Decreto-Lei 9.759/2019, visando extinguir vários Conselhos de Políticas Públicas do país.
} 
em diferentes áreas de políticas públicas (Lopez e Pires, 2010). ${ }^{6}$ Orçamentos participativos e ouvidorias também são considerados exemplos de instituições participativas no país, muito embora essas modalidades apresentem trajetórias de expansão opostas. ${ }^{7}$

Diante desse cenário, algumas tendências analíticas possibilitaram desdobramentos interessantes nos últimos anos, seja pelo desenvolvimento de estudos que visam refinar metodologias de avaliação da efetividade da participação e/ou da deliberação (Avritzer e Souza, 2013; Pires, 2011), seja pelo avanço na avaliação dos processos e mecanismos de inclusão política pelo registro da representação, adensando o campo do conhecimento sobre a pluralização do exercício da representação política no âmbito das instituições participativas, o que vem demandando maiores cuidados para diferenciar as capacidades inclusivas e as exigências de critérios de representatividade perante os seus públicos-alvo (Almeida, 2014; Gurza Lavalle, Houtzager e Castello, 2006; Gurza Lavalle e Castello, 2008; Isunza Vera e Gurza Lavalle, 2012; Lüchmann, 2007, 2010).

De outra forma, percebe-se também um movimento no sentido de situar as IP em um contexto sociocultural e político mais amplo, especialmente no sentido de compreender, a partir de diferentes frentes teóricas, essas práticas institucionais em uma perspectiva relacional e multidimensional. $\mathrm{O}$ estudo do Instituto de Pesquisas Econômicas Avançadas (Ipea) (Silva, Lopez e Pires, 2010, p. 32) é um exemplo nesse sentido, ao chamar a atenção para a necessidade de se analisar a multidimensionalidade ${ }^{8}$ da experiência

\footnotetext{
6 Considerados conselhos centrais em sua área de política pública, contando com representação do governo e da sociedade civil, e criados por atos normativos.

7 Enquanto as ouvidorias se multiplicam por todas as esferas de governo em todo o país, os orçamentos participativos vêm sofrendo um processo de extinção, em especial a partir das últimas eleições municipais de 2016.

8 Nesse estudo a multidimensionalidade é composta pelo sistema representativo, pelas instituições participativas e pelo sistema de controles da burocracia.
} 
democrática brasileira "a partir de um conjunto variado de processos, procedimentos e espaços institucionais reciprocamente constitutivos, que, por isso mesmo, não podem mais ser reduzidos a nenhuma das dimensões e terminologias específicas que comumente são mobilizadas para descrever sistemas democráticos". Os debates mais recentes na teoria deliberativa a partir de um giro sistêmico (Dryzek, 2010) também têm ampliado as lentes para os diferentes espaços, processos e padrões de ação política, e permitido abrigar diferentes análises sobre as práticas e instituições políticas nas sociedades contemporâneas. Faria (2012, p. 5), por exemplo, mobilizou a ideia de sistema deliberativo para pensar as dinâmicas de participação, representação e deliberação junto às conferências de políticas públicas no Brasil caracterizadas "por múltiplas esferas, com diferentes padrões de ação, mas cujo objetivo final é a produção de uma agenda pública que sensibilize o poder público acerca de suas necessidades reais e simbólicas". Assim, ganha vulto a preocupação em reconhecer e articular os diferentes espaços - e momentos - baseados em pressupostos da participação, da representação e da deliberação. De fato, as principais instituições participativas, como são os conselhos e as conferências de políticas públicas, parecem desenhar um sistema que acomoda essas diferentes, embora articuladas, lógicas e práticas de ação política. Digno de nota na busca por uma maior articulação foi o processo de construção, durante o governo de Dilma Rousseff, de um sistema de participação que culminou no Decreto no 8.243/2014 que visava instituir a Política e o Sistema Nacional de Participação Social. No entanto, em que pese os avanços daquele decreto, inclusive incorporando outros instrumentos de participação, como os fóruns, audiências públicas e ambientes virtuais, a ideia de sistema permaneceu ainda muito vaga, conforme Almeida (2017), ficando mais restrita às IP mais consolidadas, como os conselhos, conferências e ouvidorias, deixando de 
fora outros mecanismos - mais individualizados ou coletivizados - de participação e consulta, e "que poderiam contribuir para a oxigenação dos demais processos de representação coletiva" (Almeida, 2017, p. 663).

Assim, para além das IP, assistimos também, nas últimas décadas, à proliferação de uma multiplicidade de novos espaços e mecanismos participativos, desenhando um quadro de inflacionamento de canais que visam algum tipo de comunicação e aproximação entre estruturas estatais e cidadãos. $\mathrm{O}$ conceito de interfaces socioestatais (Hevia e Isunza Vera, 2010; Isunza Vera e Gurza Lavalle, 2010; Pires e Vaz, 2014) parece bastante apropriado para a identificação desse fenômeno, na medida em que, embora incorpore as IPs, alarga, em muito, as modalidades de interação entre sociedade e Estado, incluindo-se as ouvidorias, audiências e consultas públicas e os contatos via internet, entre vários outros dispositivos direcionados à participação da população junto às instâncias governamentais.

Essa proliferação de interfaces socioestatais coloca novos desafios no campo da teoria democrática, na medida em que, diferente de se constituírem em sistemas integrados que articulam participação, deliberação e representação, são criadas e funcionam, em boa medida, de forma desarticulada e obedecendo a propósitos e objetivos de acordo com os interesses e estratégias político-governamentais e de acordo com os diferentes contextos, áreas de políticas públicas, e dinâmicas institucionais. Diante disso, é compreensível o diagnóstico formulado por Hevia e Isunza Vera (2010) ao apontarem para déficits de participação em contextos de ampliação e de pluralização das ofertas de espaços de interface socioestatal. Fung (2015) também elenca alguns problemas e desafios diante da proliferação de mecanismos participativos, em especial, a inconstância dada por origens de caráter oportunista, gerando iniciativas, na sua maioria, não sistemáticas, além da sua trivialidade, ou seja, da expansão 
de canais de participação com baixo poder de influência sobre a agenda e os resultados das políticas públicas. ${ }^{9}$

Esse processo de pluralização e fragmentação de mecanismos participativos suscita pelo menos dois conjuntos de questões. Por um lado, um bloco de questões relativas às origens e à vocação das interfaces. Como foram criadas e quais são os sentidos desses programas participativos? Quem são os atores (sociais e governamentais) que atuam nesses espaços, e quais são as demandas e interesses que representam? Um segundo bloco de questões diz respeito às articulações entre os diferentes mecanismos e padrões de interfaces socioestatais, e que podemos denominar da problemática da interface das interfaces socioestatais. O problema, aqui, embora incorpore as preocupações relativas à combinação entre mecanismos de participação, representação e deliberação, diz respeito à avaliação da coexistência de diferentes espaços e mecanismos de participação. Qual é a vocação das diferentes interfaces no interior do conjunto mais amplo de mecanismos e instituições participativas? Em que medida esses mecanismos dialogam entre si na formação de um sistema participativo e/ou deliberativo, garantindo algum nível de retroalimentação? Ou são criados de forma isolada e fracionada, obedecendo a distintas lógicas e interesses político-governamentais?

Tendo em vista abordar essas questões, buscamos, na literatura, algumas dimensões analíticas que implicam em considerar elementos do Estado, uma vez que as interfaces visam materializar a abertura de diferentes dispositivos estatais para a vocalização de demandas e interesses da sociedade.

\footnotetext{
9 Um exemplo dado pelo autor é o do banco do parque. "Quando uma cidade concede aos moradores o poder para decidir qual cor que seus bancos do parque deveriam ser pintados, isso aumenta a participação cidadã, mas não de forma significativa [...] No limite, a participação se torna trivial: os participantes exercem pouca influência sobre resultados, a agenda de questões que eles consideram pode ser altamente constrangida, ou os recursos e a autoridade investidos em uma participação podem ser muito pequenos" (Fung, 2015, p. 8-9).
} 
Assim, alguns condicionantes para o funcionamento de mecanismos participativos têm sido identificados na literatura, sejam eles de natureza externa ou interna aos mesmos. Esses mecanismos envolvem atores, setores e recursos diversos, e dependem dos diferentes contextos sociais, culturais e institucionais (Hevia e Isunza Vera, 2010; Silva, 2011; Wampler, 2011)..$^{10}$

Com o propósito de apresentar algumas dessas dimensões analíticas, o trabalho está dividido em três seções. Na primeira seção apresentamos as principais definições de IPs e de interfaces socioestatais encontradas na literatura. A segunda seção é reservada para a apresentação, seguindo o estudo de Hevia e Isunza Vera (2010), de uma tipologia das interfaces, bem como de uma listagem dos principais tipos de interfaces socioestatais em vigência no Brasil, tanto no plano federal (Pires e Vaz, 2014), quanto municipal (tomando como exemplo o município de Florianópolis). A terceira seção apresenta algumas dimensões analíticas que são aqui consideradas centrais para a avaliação das articulações entre as diferentes interfaces socioestatais.

\section{Interfaces socioestatais e instituições participativas}

Como vimos, no Brasil as instituições participativas vêm ocupando um lugar de destaque nos estudos sobre as inovações participativas, como atestado pelo acúmulo de pesquisas sobre as modalidades de IPs mais conhecidas: os Conselhos Gestores, os Orçamentos Participativos e as Conferências de Políticas Públicas. De acordo com Borba (2011, p. 66), um primeiro esforço no sentido de conceituar as instituições participativas pode ser encontrado

\footnotetext{
10 O trabalho de Silva (2011), por exemplo, voltado para a análise das IPs, procura avançar na identificação e sistematização dessa complexidade, destacando para a necessidade de situar as IPs no âmbito mais geral das estratégias, dos repertórios e das capacidades de atuação dos diversos atores; situar as IPs nos ciclos de produção e implementação de políticas públicas; analisar as legislações; e o volume e tipo de recursos envolvidos.
} 
no trabalho de Avritzer (2008). Neste trabalho, o autor apresenta a seguinte definição: "Por IPs entendemos formas diferenciadas de incorporação de cidadãos e associações da sociedade civil na deliberação sobre políticas" (Avritzer, 2008, p. 45), destacando, em sua análise comparativa, os casos de orçamento participativo, conselhos de políticas, e os planos diretores municipais. As IPs dizem respeito, portanto, a um conjunto de espaços que se institucionalizam enquanto fóruns públicos de deliberação que não têm sido, conforme alerta o autor, cobertos pela ciência política, tradicionalmente voltada para os estudos das instituições formais da democracia eleitoral.

Uma segunda abordagem em torno da definição de IPs é encontrada no trabalho de Cortes (2011, p. 137), referindo-se aos "mecanismos de participação criados por lei, emendas constitucionais, resoluções ou normas administrativas governamentais que permitem o envolvimento regu20 lar e continuado de cidadãos com a administração pública, tanto diretamente quanto através de representantes, como ocorre com maior frequência”. O caráter institucional desses mecanismos é assegurado, de acordo com a autora, pelo fato de não serem "experiências episódicas ou eventuais de participação em projetos ou programas governamentais ou de organizações da sociedade civil ou do mercado. Ao contrário, estão instituídas como elementos característicos da gestão pública brasileira" (Cortes, 2011, p. 137). Seguindo este critério, e voltando o olhar para a esfera municipal, a autora elenca os seguintes tipos de IPs: mecanismos de consulta individual; conselhos gestores, conferências de políticas públicas e orçamentos participativos.

Um terceiro esforço de conceituação pode ser encontrado no trabalho de Lopez e Pires (2010). De acordo com os autores, as IPs seriam "processos deliberativos que transcendem os momentos eleitorais e propiciam alternativas de inclusão dos interesses dos grupos organizados no cotidiano 
da esfera política, fomentando, ao mesmo tempo, a organização política destes grupos e criando novas formas de mediação representativa entre Estado e sociedade" (Lopez e Pires, 2010, p. 565). Os principais exemplos apontados no estudo são as conferências, os conselhos e os orçamentos participativos. Aqui, o caráter institucional desses formatos é ressaltado pela capacidade de se constituírem a partir de normas e procedimentos que estruturam e impactam a ação política e social.

Embora compartilhem um núcleo comum, podemos perceber algumas variações nessas definições. No primeiro caso, o caráter deliberativo das políticas é apontado como elemento central, e está relacionado aos fóruns públicos que contam com a participação de uma diversidade de atores políticos e sociais. No segundo, encontramos as dimensões da formalidade, regularidade e estabilidade no campo da gestão pública brasileira, marcando o caráter da institucionalidade. A terceira definição, além de resgatar a dimensão deliberativa e de enfatizar os elementos da estabilidade e da formalidade, ressalta o poder das instituições em organizar, impactar e/ou constranger comportamentos e dinâmicas societais, estruturando a ação política e social. ${ }^{11}$

Sem negar os reconhecidos méritos desses esforços conceituais, o fato é que eles suscitam pelo menos duas importantes reflexões. Em primeiro lugar, apesar dos ganhos da categoria IP em identificar e caracterizar um conjunto de instituições que se abrem para a participação, em especial as organizações da sociedade civil, "ela corre o risco de unificar um campo muito heterogêneo, bloqueando a capacidade de apreender a diversidade de suas configurações empíricas e, especialmente,

\footnotetext{
11 Essas diferenças e aproximações conceituais espelham as diferenças e aproximações dos casos ilustrados. Assim, se os conselhos e as conferências podem ser mais facilmente identificados como IPs, essa identificação se atenua frente a exemplos como o dos mecanismos de consulta individual, pela ausência do critério da deliberação, e dos programas de orçamento participativo, por não cumprirem com o critério da estabilidade e da permanência no tempo.
} 
de seu funcionamento e resultados" (Silva, 2011, p. 234). O reconhecimento da diversidade de IPs tem motivado o desenvolvimento de estudos que procuram tipificar essas práticas a partir de diferentes critérios, a exemplo do trabalho de Hevia e Isunza Vera (2010) que elenca pelo menos três dimensões de classificação, quais sejam, o maior ou menor vínculo com o Estado, o tipo de envolvimento da população (se em caráter individual e/ou coletivo), e a maior ou menor capacidade de influência e de poder sobre o mesmo.

Em segundo lugar, e como ressaltado por Pires e Vaz (2014), em que pese a importância dessa evolução e do acúmulo no campo mais amplo de estudos sobre as IPs e a democracia, o privilégio dado aos estudos voltados para os fóruns públicos, em especial aqueles que contam com a participação dos atores sociais coletivos, têm restringido o campo de estudos sobre as diferentes modalidades de interação entre Estado e sociedade. Assim,

Passamos a compreender cada vez melhor a ocorrência de conselhos, orçamentos participativos e, mais recentemente, de conferências, e nos distanciamos cada vez mais da observação de outras formas de interação Estado-sociedade igualmente relevantes e cotidianas na gestão de políticas públicas, como reuniões entre grupos de interesse e atores governamentais, audiências e consultas públicas e ouvidorias, sem mencionar as formas não presenciais e virtuais mediadas por ferramentas de tecnologia de informação. (Pires e Vaz, 2014, p. 64)

O conceito de interfaces socioestatais procura suprir esta lacuna ao sinalizar para um panorama mais amplo de interações entre Estado e sociedade, contribuindo para iluminar um campo muito mais amplo de dispositivos e de repertórios de comunicação entre atores sociais e governamentais (Pires e Vaz, 2014). 
Baseados nos trabalhos de Long (1999) e Roberts (2001), Isunza Vera e Hevia (2006, p. 61) definem o conceito de interface como

Un espacio de intercambio y conflicto en el que ciertos actores se interrelacionan no casual sino intencionalmente. Un tipo especial de interfaz es el espacio donde actores societales y estatales se encuentran (por lo tanto, las definimos como interfaces socioestatales). Estas interfaces socioestatales están determinadas estructuralmente tanto por la política pública como por los proyectos sociopolíticos de los actores (estatales y societales) concernidos.

De acordo com Long (1999), embora a palavra "interface" sugira as relações e/ou encontros (ou confrontos) face-a-face, as interações de interface são múltiplas e complexas, e implicam em uma relação continuada no tempo, tornando-se uma prática organizada de relacionamentos e intencionalidades pautada em regras, sanções e procedimentos tendo em vista lidar com interesses e percepções conflitantes. Assim, para o autor, se as interações de interface pressupõem algum grau de interesse comum, elas também materializam relações conflituosas, em função dos interesses e objetivos contraditórios ou das relações desiguais de poder, fornecendo os meios pelos quais os indivíduos ou grupos definem os seus pontos de vista perante aqueles que defendem pontos de vista diferentes e/ou opostos. Trata-se, portanto, de um processo interativo e comunicativo que envolve diálogo, contestação de significados, controle, autoridade e poder.

Voltado para a análise das políticas sociais na América Latina, o trabalho de Roberts (2001) aponta para o fenômeno da multiplicação de situações de interface entre agências governamentais, organizações não governamentais (ONG), cidadãos e organizações comunitárias. 
Esse crescimento estaria relacionado, de acordo com o autor, ao contexto neoliberal de reorganização no papel dos Estados, por um lado, e ao processo de democratização política, por outro, desaguando em uma crescente ampliação do peso do governo local na promoção da política social. O Brasil ocuparia um lugar de destaque neste cenário, apresentando "posiblemente el sistema más descentralizado de política social y tal vez el espectro más grande de actores sociales significantes en política” (Roberts, 2001, p. 7).

Como vimos, houve, de fato, nas últimas décadas, uma proliferação de mecanismos participativos no país, em que pese serem, em boa medida, dispositivos frágeis e, em muitos casos, inócuos em sua capacidade de promover deliberação democrática. Para Pedro Pontual (apud Gurza Lavalle e Swacko, 2014, p. 94), por exemplo:

Diferentemente das décadas de 1970 e 1980, nas quais o discurso participacionista vinha muito ligado às lutas democráticas, no início dos anos 2000, a participação, ao mesmo tempo em que se generaliza, é também pasteurizada, por assim dizer. Ou seja, havia metodologias e projetos muito distintos conforme o ator social e o lugar social de onde esse discurso participacionista era enunciado. Até o setor empresarial começa a falar em participação ligada à ideia de responsabilidade social. Em paralelo, áreas do Estado antes pouco permeáveis à participação começam a falar de participação num sentido muito restrito, às vezes só no sentido de consultas breves e pontuais sobre determinados aspectos, mas que não tinham incidência efetiva sobre a mudança das políticas”.

Assim, testemunhamos, no caso da realidade brasileira, pelo menos durante os últimos trinta anos, em especial a partir da Constituição de 1988 até o final do governo de Dilma Rousseff, a criação de diferentes dispositivos de 
interfaces no âmbito das estruturas governamentais: ouvidorias, sítios na internet, programas governamentais como os orçamentos participativos, consultas públicas, conselhos, conferências, audiências públicas, entre outras, materializando diferentes relações entre Estado e sociedade em um cenário com múltiplos pontos de acesso, preenchido por diferentes formatos e propósitos. ${ }^{12}$ Diante dessa variedade, algumas tipologías vêm sendo criadas, como veremos a seguir.

\section{Tipologia das interfaces socioestatais}

Tendo em vista a crescente complexidade das relações entre sociedade civil e Estado, Hevia e Isunza Vera (2010), apresentam uma tipologia das interfaces socioestatais baseada em duas lógicas - cognoscitiva e política - que se desdobram em seis tipos de relações, conforme apresentado a seguir:

Os tipos cognoscitivos são:

1. Interface de contribuição (participação social informativa) $S C \rightarrow E$, na qual a sociedade civil informa o Estado (ouvidorias, consultas, etc)

2. Interface de transparência (informação governamental) $S C \leftarrow E$, na qual o Estado informa a sociedade civil (páginas de internet, campanhas governamentais, etc)

3. Interface comunicativa (colaboração informativa) $S C \leftrightarrow E$, na qual sociedade civil e Estado se informam mutuamente, se comunicam (audiências públicas e conselhos consultivos com caráter não vinculante, etc.)

\footnotetext{
12 Essas diferenças não significam, necessariamente, que algumas interfaces sejam a priori mais importantes do que outras. Como exemplificado por Gurza Lavalle e Isunza Vera (2010, p. 34), diferente de serem considerados dispositivos sem importância frente aos mecanismos coletivos, a exemplo dos conselhos gestores, os sistemas de queixas podem ser "extremamente útiles no solo para la correción de distorciones administrativas, sino también para la racionalización del poder".
} 
Os tipos políticos são:

4. Interface mandatária (democracia direta, controle social) $S C \Rightarrow E$, na qual a sociedade civil controla, domina ou dirige o Estado (referendo, plebiscito, iniciativa popular, etc)

5. Interface de transferência (políticas públicas executadas pela sociedade civil) $S C \Leftarrow E$, na qual o Estado controla, domina ou dirige a sociedade civil (execução de projetos sociais por ONGs, por exemplo)

6. Interface cogestiva (cogestão de políticas públicas) $S C \Leftrightarrow E$, na qual a sociedade civil e o Estado mantém una relação de cogestão (conselhos cujas decisões são de caráter vinculatório). Adaptado de Hevia e Isunza Vera (2010, p. 65-66).

As trocas de informação e/ou de poder são, portanto, 26 os bens de intercâmbio considerados centrais na construção dessa tipologia das interfaces socioestatais. Assim, encontramos uma variação de relações e/ou encontros entre agências governamentais e setores sociais (individuais ou coletivos) que conformam uma multiplicidade de mecanismos de exercício de influência e/ou de poder. No caso brasileiro, uma sistematização dessa multiplicidade pode ser visualizada no Quadro 1, que apresenta os tipos e as formas de interfaces encontradas na esfera federal.

Quadro 1

Tipos e formas de interface socioestatal nos programas federais

\begin{tabular}{|l|l|}
\hline \multicolumn{1}{|c|}{ Tipo } & \multicolumn{1}{c|}{ Formas de interação } \\
\hline Conselho & $\begin{array}{l}\text { Programa (ou seus subcomponentes) submetido a discussões em algum } \\
\text { conselho nacional }\end{array}$ \\
\hline Conferência & $\begin{array}{l}\text { Programa (ou seus subcomponentes) submetido a discussões em alguma } \\
\text { conferência nacional }\end{array}$ \\
\hline
\end{tabular}

(continua) 
Quadro 1 (continuação)

\begin{tabular}{|l|l|}
\hline \multicolumn{1}{|c|}{ Tipo } & \multicolumn{1}{c|}{ Formas de interação } \\
\hline $\begin{array}{l}\text { Consulta } \\
\text { pública }\end{array}$ & $\begin{array}{l}\text { Programa (ou seus subcomponentes) envolvendo algum processo de } \\
\text { consulta pública sobre aspectos de seu funcionamento, normatização etc. }\end{array}$ \\
\hline $\begin{array}{l}\text { Audiência } \\
\text { pública }\end{array}$ & $\begin{array}{l}\text { Programa (ou seus subcomponentes) envolvendo algum processo de } \\
\text { audiência pública sobre suas ações, intervenções, iniciativas etc. }\end{array}$ \\
\hline Ouvidoria & $\begin{array}{l}\text { Atuação de ouvidoria, vinculada a algum órgão (do próprio setor } \\
\text { ou não), incidindo sobre programa - canalização de denúncias, } \\
\text { reclamações, críticas, sugestões etc. }\end{array}$ \\
\hline $\begin{array}{l}\text { Reunião com } \\
\text { grupos de } \\
\text { interesse }\end{array}$ & $\begin{array}{l}\text { Reuniões entre associações civis, empresariais, sindicais, ou movimentos } \\
\text { sociais e órgãos ou representantes governamentais; mesas de diálogos, } \\
\text { fóruns, grupos de trabalho e outras formas de interação pouco } \\
\text { institucionalizadas que incidem sobre aspectos da gestão de programas } \\
\text { (conteúdos, metas, formas de implementação, avaliação etc.) }\end{array}$ \\
\hline Outros & $\begin{array}{l}\text { Sítios de internet, telefones disponibilizados (SAC, disque denúncia etc.), } \\
\text { bem como ações pontuais com o objetivo de divulgar aspectos de } \\
\text { programas. }\end{array}$ \\
\hline
\end{tabular}

Fonte: Pires e Vaz (2014).

O estudo aponta para um incremento e diversificação dos tipos de interfaces adotados no âmbito federal, com maior incidência nas áreas sociais. Além disso, os autores registram a ocorrência de um certo padrão entre tipos de interfaces e áreas de políticas públicas: "Enquanto interfaces como conselhos e conferências apresentaram maior vínculo relativo aos programas da área de Proteção e Promoção Social, audiências e consultas públicas e reuniões com grupos de interesse se apresentaram mais associadas às temáticas de Infraestrutura e Desenvolvimento Econômico, respectivamente" (Pires e Vaz, 2014, p. 86). Essas diferenças também foram encontradas no estudo sobre a realidade mexicana, identificando uma maior diversidade de interfaces socioestatais no campo das políticas sociais, ao contrário dos campos da seguridade pública e da política fiscal e financeira (Hevia e Isunza Vera, 2010). Daí o reforço da tese que atesta para a baixa porosidade participativa no núcleo duro da política pública, "en el que la participación ciudadana es periférica, prácticamente irrelevante" (Hevia e Isunza Vera, 2010, p. 100). 
A ampliação dos olhares para os dispositivos encontrados no âmbito municipal nos permitiu identificar, além dos tipos encontrados no âmbito federal, outras modalidades, conforme apresentado no Quadro 2, e que fez readaptações no sentido de apresentar: i) o tipo da interface; ii) a sua classificação de acordo com os seis tipos ideais identificados por Hevia e Isunza Vera (2010); e iii) uma breve definição de cada tipo.

Quadro 2

Tipos de interface socioestatal na estrutura do governo municipal de Florianópolis

\begin{tabular}{|c|c|c|}
\hline Interface & Tipo* & Definição \\
\hline Conselhos de Políticas & 6 & $\begin{array}{l}\text { Órgãos colegiados permanentes, inseridos na } \\
\text { estrutura do Estado e instituídos por ato normativo, } \\
\text { compostos por representantes do governo e da } \\
\text { sociedade civil organizada, e voltados para a } \\
\text { formulação, o controle e a definição de políticas nas } \\
\text { respectivas áreas de atuação. }\end{array}$ \\
\hline Orçamentos Participativos & 6 & $\begin{array}{l}\text { Programas governamentais que visam discutir e } \\
\text { definir a destinação de parte do orçamento municipal } \\
\text { com a população local por meio de procedimentos e } \\
\text { regras de participação e de distribuição dos recursos. }\end{array}$ \\
\hline Conferências & 3 & $\begin{array}{l}\text { Encontros periódicos que reúnem setores sociais e } \\
\text { governamentais para a discussão e apresentação } \\
\text { de propostas e diretrizes em sua respectiva área de } \\
\text { política. Ocorrem de forma escalonada, iniciando } \\
\text { na esfera municipal e progredindo, por meio } \\
\text { da representação de delegados, para as etapas } \\
\text { estaduais e nacional. }\end{array}$ \\
\hline Conselhos consultivos & 3 & $\begin{array}{l}\text { Órgãos colegiados (permanentes ou não) voltados } \\
\text { para a emissão de opiniões e sugestões sobre } \\
\text { assuntos relacionados com o tema da política em } \\
\text { sua respectiva área de atuação. }\end{array}$ \\
\hline Audiências públicas & 3 & $\begin{array}{l}\text { Consultas abertas à população promovidas } \\
\text { pelo poder público diante de uma temática } \\
\text { específica, em geral vinculada a um processo } \\
\text { decisório, como a aprovação de planos diretores, } \\
\text { a implementação de uma obra, ou a elaboração } \\
\text { de uma determinada política pública. São } \\
\text { obrigatoriamente presenciais. }\end{array}$ \\
\hline
\end{tabular}


Quadro 2 (continuação)

\begin{tabular}{|c|c|c|}
\hline Interface & Tipo* & Definição \\
\hline Consultas públicas & 1 & $\begin{array}{l}\text { Consultas relativas a diferentes campos de políticas. } \\
\text { Diferente das audiências públicas, podem ocorrer } \\
\text { de modo não presencial. }\end{array}$ \\
\hline Facebooks e blogs & 2 & $\begin{array}{l}\text { Canais de informação entre administração e } \\
\text { usuários/cidadãos }\end{array}$ \\
\hline Prefeitura nos bairros & 3 & $\begin{array}{l}\text { Programa de governo itinerante tendo em vista } \\
\text { promover encontros entre o prefeito e seu secretariado } \\
\text { e a população, ouvindo as suas demandas e } \\
\text { reclamações em suas regiões de moradia. }\end{array}$ \\
\hline $\begin{array}{l}\text { Reuniões com grupos de } \\
\text { interesse }\end{array}$ & 3 & $\begin{array}{l}\text { Encontros entre associações civis, empresariais, } \\
\text { sindicais, ou movimentos sociais e órgãos ou } \\
\text { representantes governamentais, fóruns, grupos } \\
\text { de trabalho e outras formas de interação pouco } \\
\text { institucionalizadas que incidem sobre aspectos da } \\
\text { área da política. }\end{array}$ \\
\hline Mesas de negociação & 3 & $\begin{array}{l}\text { Fóruns permanentes de negociação entre gestores, } \\
\text { empregadores e profissionais/trabalhadores da área } \\
\text { da política tendo em vista discutir sobre questões } \\
\text { pertinentes à força de trabalho. }\end{array}$ \\
\hline Ouvidorias & 1 & $\begin{array}{l}\text { Canais de comunicação do cidadão para apresentar } \\
\text { sugestões, críticas, reclamações, denúncias, } \\
\text { solicitação de informações pertinentes ao âmbito } \\
\text { da Administração Pública. Além das Ouvidorias dos } \\
\text { cidadãos, encontramos também Ouvidorias } \\
\text { dos servidores. }\end{array}$ \\
\hline $\begin{array}{l}\text { Pesquisas de satisfação } \\
\text { de usuários }\end{array}$ & 1 & $\begin{array}{l}\text { Disponibilização de questionários (online e } \\
\text { presenciais) de avaliação dos serviços oferecidos } \\
\text { aos usuários, utilizando os resultados para subsidiar } \\
\text { ações de melhoria nos serviços. }\end{array}$ \\
\hline Denúncias & 1 & $\begin{array}{l}\text { Canais para denúncias variadas relativas a } \\
\text { problemas de atendimento, falta de serviços, etc. } \\
\text { Exemplo Vigilância Sanitária }\end{array}$ \\
\hline Outros & 1 & E-mails, telefones, encaminhamento de Ofícios, etc. \\
\hline
\end{tabular}

Legenda: 1 - Interface informativa - a sociedade informa o Estado; 2 - Interface de transparência - o Estado informa a sociedade; Interface comunicativa - sociedade e Estado se informam mutuamente; 3 -Interface mandatária - a sociedade controla, domina ou dirige o Estado; 5 - Interface de transferência de políticas o Estado controla, domina ou dirige a sociedade; 6 - Interface de cogestão Estado e sociedade compartilham o poder de gestão.

Fonte: Mapeamento realizado nos sites da Prefeitura, adaptado de Pires e Vaz (2014). 
Destaque para o crescimento das ferramentas digitais nesse campo, o que vem estimulando o desenvolvimento de estudos voltados para a criação e o funcionamento das diferentes modalidades de e-participação, e que dizem respeito à abertura dessas oportunidades de consulta e diálogo entre governos e cidadãos (Medaglia, 2012).$^{13}$

Diante desse quadro, podemos dizer que, e seguindo a reflexão de Hevia e Isunza Vera, (2010, p. 111) se há um déficit de participação, este déficit não parece estar na oferta de espaços e mecanismos participativos, mas sim na forma como eles são utilizados. Manipulação política, fragmentação e superposição de funções, invisibilidade, baixa participação, falta de comprometimento político, são alguns dos problemas identificados na literatura. Tendo em vista analisar as potencialidades, limites e variações no campo das inovações participativas, vários elementos, ou condicionantes, têm sido identificados na literatura, sejam eles 30 de natureza externa ou interna aos programas e/ou interfaces. Esses elementos envolvem atores, setores e recursos diversos, e dependem dos diferentes contextos sociais, culturais e institucionais (Hevia e Isunza Vera, 2010; Silva, 2011; Wampler, 2011;). No intuito de contribuir com esse campo de estudos, e tendo em vista avaliar possíveis articulações entre diferentes modalidades de interface socioestatal, apresentamos, a seguir, elementos analíticos da literatura das instituições participativas e das políticas públicas, em especial no que diz respeito ao conceito de intersetorialidade e alguns de seus condicionantes, seja no plano institucional (trajetórias, recursos e regras), seja no da atuação dos agentes (políticos, burocráticos e sociais).

\footnotetext{
13 Buscando investigar o emprego das TICs para o fomento da participação democrática nos governos de importantes cidades brasileiras, Silva (2005) conclui que há uma subutilização das potencialidades democráticas dessas ferramentas.
} 


\section{Interfaces sociestatais: desafios e dimensões analíticas}

No âmbito da teoria democrática e voltado para o campo das práticas e instituições participativas, diversos elementos analíticos têm sido apontados como centrais para a compreensão e a avaliação dessas experiências. Fung (2006), por exemplo, apresenta três dimensões que permitem identificar as variações dos modelos ou instrumentos de participação, e que dizem respeito à identificação de quem participa; como ocorre a participação e qual é o sentido, ou o grau decisório da participação. ${ }^{14}$ Assim, além dos atores, os arranjos institucionais e as competências decisórias são consideradas dimensões centrais nos estudos das variadas formas de participação. Buscando sistematizar a produção acadêmica sobre o tema da e-participação na esfera internacional, Medaglia (2012) ressalta, entre outras categorias analíticas, a dimensão dos atores que participam, ou de quem pode participar (cidadãos, políticos, instituições governamentais, organizações voluntárias), e os fatores do contexto institucional dos programas e dispositivos participativos, como a disponibilidade de informação, infra-estrutura e de tecnologias subjacentes, a acessibilidade, questões políticas e legais, e a organização governamental (Medaglia, 2012, p. 348). Estudos sobre os orçamentos participativos têm mobilizado algumas variáveis analíticas que operam na maior ou menor capacidade - ou sucesso - em provocar resultados que apontam para avanços democráticos, como a dimensão do associativismo, ou da configuração e atuação dos atores da sociedade civil; a vontade e/ou comprometimento político dos respectivos governantes; e o desenho institucional (Avritzer e Navarro, 2003; Borba e Lüchmann, 2007; Lüchmann, 2014; Sintomer, Herzberg e Rocke, 2012).

14 Quem participa? Como os participantes se comunicam e tomam decisões? Quais são as conexões entre as discussões e as ações e políticas adotadas? (Fung, 2006; 2015). 
Além dessas preocupações em avaliar as características dos diferentes formatos participativos, vários estudos vêm apontando para a necessidade de se olhar para as dinâmicas participativas de uma forma mais abrangente, seja no sentido de analisá-las no âmbito das diferentes estruturas de poder político (Almeida e Tatagiba, 2012; Gurza Lavalle, Houtzager e Castello, 2006), seja no sentido de situar a sua inserção em uma "arquitetura da participação", ou em sistemas deliberativos, formados por múltiplos canais de engajamento. Para o primeiro caso, a ênfase recai na problemática da superposição de funções e de poderes decorrente da introdução de instituições participativas na esfera estatal. Gurza Lavalle; Houtzager e Castello (2006), por exemplo, alertam para as características de uma estrutura federativa assentada na competência dos executivos e legislativos em deliberar e sancionar as políticas e os recursos, o que tem levando as inovações participativas a exercerem funções concorrentes de representação política, suscitando conflitos e tensões com outros poderes.

Para o segundo caso, o foco recai para a análise da "arquitetura da participação" (Isunza Vera e Gurza Lavalle, 2012; Teixeira, Souza e Lima, 2012), ${ }^{15}$ ou de um sistema deliberativo mais abrangente (Faria, Silva e Lins, 2012), ou ainda, dos "múltiplos canais de engajamento" (Spada e Allegretti, 2017). A ideia de arquitetura da participação supõe a necessidade de incorporar os "vários dispositivos sociais e transversais simultaneamente articulados entre si, e conectados com a sociedade civil e com o Estado, como demonstrado pela conexão entre conselhos gestores de políticas, por um lado, e fundos setoriais, fóruns da sociedade civil e conferências convocadas pelo Estado, por outro" (Isunza Vera e Gurza Lavalle, 2012, p. 120). No campo da

15 O trabalho de Teixeira, Souza e Lima (2012, p. 8), trata esse termo de forma mais abrangente, entendendo a arquitetura da participação "como conjunto de instâncias participativas institucionalizadas que podem ou não estar articuladas entre si”. 
democracia deliberativa, uma perspectiva sistêmica tem, além de buscado integrar participação, deliberação e representação (Faria et al, 2012; Hendriks, 2006), apontado para a necessidade de se identificar as características dos Estados e dos sistemas políticos em que as experiências deliberativas estão inseridas (Dryzek, 2010).

Inserido nesse campo, e tendo como foco as inovações participativas multicanais, o trabalho de Spada e Allegretti (2017) procura analisar os múltiplos canais de engajamento no interior de determinadas inovações democráticas, como são os casos de orçamentos participativos e das assembleias de cidadãos que ocorrem por diferentes ferramentas participativas (encontros grupais, assembleias, eleições online etc.). De acordo com os autores, as inovações democráticas multicanais são aquelas instituições que projetam diferentes espaços e formatos voltados a diferentes segmentos da população tendo em vista alcançar, ou incluir, setores mais amplos. Assim, a integração de múltiplos canais de engajamento no interior de uma inovação participativa permitiria a diversificação e a acomodação de demandas e interesses de diferentes tipos de pessoas na sociedade, ganhando eficiência por meio do compartilhamento de recursos e informações. ${ }^{16}$

A proposta investigativa, aqui, coloca-se em uma posição que, embora dialogue com esses dois caminhos analíticos, busca ir além de uma análise sistêmica, ou voltada para os programas multicanais, na medida em que consiste em analisar o lugar, e as interelações, entre as diferentes modalidades de interfaces, sejam inseridas, ou não, em sistemas

\footnotetext{
16 Um exemplo apontado no trabalho é o Sistema Municipal de Participação implementado no município de Canoas (RS), que criou 13 ferramentas (online e offline) voltadas aos diferentes canais de diálogo com a sociedade. Essas ferramentas, de acordo com Spada e Allegretti (2017), incorporam diferentes segmentos da população, formando um complexo sistema participativo que permite à cidade propor e acompanhar as questões levantadas por indivíduos e grupos em cada um desses canais diferentes.
} 
mais integrados, e/ou que comportam múltiplos canais de participação, deliberação e/ou representação.

Assim, é certo que muitos elementos estão em jogo nesse campo de estudos sobre as interfaces, implicando complexas configurações. Como apresentado no Quadro 2, estamos diante de uma multiplicidade de canais interativos, com origens e atribuições muito diversas. Cada vez mais os governos recorrem a múltiplos espaços e fluxos de informação para identificar problemas e demandas e definir agendas e programas políticos (Wampler, 2011). Isso implica em múltiplos pontos de contato com a sociedade, conformando, em regra, um quadro de fragmentação, dispersão e de superposição institucional.

No caso brasileiro, a literatura destaca a importância da Constituição de 1988 no processo de ampliação da participação e de criação de mecanismos e instituições de controle social e de responsabilização e prestação de contas, momento que foi fortalecido "pela agenda internacional ligada ao New Public Management ${ }^{17}$ (Nova Gestão Pública - NGP) ao longo dos anos de 1990. A ideia central era a necessidade de ampliação da transparência e responsabilização dos agentes estatais, elemento imprescindível para que o Estado atuasse de maneira mais condizente com um contexto democrático" (Lotta, Oliveira e Cavalcante, 2016, p. 16). Conceitos como os de governança em rede e governança eletrônica passaram a ocupar um lugar de destaque, em especial pela importância dos processos de controle social e de accountability por meio da criação de novas estruturas e mecanismos de consulta e/ou participação social no âmbito das agências estatais. Assim, e diferente de um modelo único

\footnotetext{
17 De acordo Cavalcante e Camões (2015, p. 5), "este modelo normativo preconizava a incorporação de técnicas da iniciativa privada para a estruturação e a gestão da administração pública com base em eficiência, eficácia e competitividade. Nas décadas de 80 e 90, a NGP se espalhou rapidamente por diversos países desenvolvidos e emergentes, sob o intenso patrocínio de organismos multilaterais".
} 
de gestão, estamos testemunhando a proliferação de um conjunto de ações, programas e ferramentas que amplificam os canais de acesso cidadão às agências estatais, em especial por meio da utilização de tecnologias de informação (Cavalcante e Camões, 2015).

No entanto, e como analisam Sorensen e Torfing (2007), essas "redes de governança" desenham dinâmicas complexas que, em muitos casos, longe de lograrem a constituição de sistemas integrados, apresentam resultados que se minam mutuamente, o que implica reconhecer que os processos de tomada de decisão política e de implementação de políticas públicas ocorrem por meio de uma variedade de instituições, atores e mecanismos formais e informais, permanentes ou episódicos. Assim, diferente de um padrão centralizado e hierárquico de governo, esses processos são multidimensionais, conformando multi-camadas que contam com múltiplos atores e distintos pontos de acesso junto aos diferentes setores de políticas públicas (Sorensen e Torfing, 2007).

No âmbito desse debate, como alertado por Torfing (2003), torna-se cada vez mais necessário avaliar até que ponto as redes de governança contribuem para uma regulação eficiente e democrática da sociedade. No caso dos estudos sobre a intersetorialidade, Cunill-Grau (2014) identifica duas perspectivas, quais sejam, a que remete às diferentes relações entre setor público, mercado e sociedade, em especial pela criação de programas que combinam público e privado por meio de parcerias e do financiamento a organizações sociais tendo em vista a provisão de serviços públicos; e a que diz respeito à dimensão multicausal dos problemas sociais, e que requer uma atuação intersetorial tendo em vista a construção de políticas com uma abordagem integral, por meio da articulação entre os diferentes setores, ou áreas das políticas públicas. 
Assim como no caso do conceito de intersetorialidade, a ideia de interfaces socioestatais apresenta um caráter relacional, e está voltada para a análise da ocorrência de algum grau de interlocução entre diferentes mecanismos de participação. Diante disso, é imperativo identificarmos a origem e os propósitos, ou a vocação das diferentes interfaces socioestatais, e avaliar o lugar que ocupam no interior dos processos de formulação e execução de políticas.

Para Comparato (2016), mesmo que de forma limitada, boa parte das interfaces, a exemplo dos conselhos, audiências públicas e leis de iniciativa popular, atuam nos estágios iniciais do ciclo das políticas públicas, contribuindo para a formação da agenda. Já outras modalidades, como os plebiscitos, referendos e instâncias do orçamento participativo podem contribuir para a tomada de decisão. Diferente desses mecanismos, as ouvidorias, ${ }^{18}$ por exemplo, atuam no momento da implementação das políticas, constituindo-se como "um instrumento valioso para os gestores públicos, que têm à disposição uma ferramenta muito útil para saber de que maneira os programas governamentais chegam ao cidadão e como este enxerga as mais variadas prestações de serviços públicos" (Comparato, 2016, p. 49). Esse mosaico participativo, formado por instrumentos e dispositivos que ocupam diferentes lugares e funções, instiga a formulação de questões acerca de sua integração, ou articulação na constituição de processos de retroalimentação. ${ }^{19}$

Em que pesem as diferenças no grau de institucionalização, um elemento central para pensarmos essas relações é

\footnotetext{
18 Em Lüchmann, Abrão e Kieling (2019) publicamos os resultados da pesquisa junto às Ouvidorias (Governo do Estado de Santa Catarina e Prefeitura Municipal de Florianópolis), mobilizando o referencial teórico aqui apresentado.

19 Que rompam com "insulamento institucional", referente ao grau de isolamento frente a outras modalidades de participação. Na literatura, o foco tem sido para avaliar o fenômeno do Insulamento Burocrático, "no qual a burocracia possui um alto grau de independência em relação aos controles político ou social" (Lotta, Oliveira e Cavalcante, 2016, p. 3).
} 
o seu vínculo com o aparelho estatal. Isso implica em averiguar não apenas as diferentes origens, os desenhos e os diferentes propósitos das interfaces, mas também as estruturas e as orientações e motivações dos agentes que operacionalizam esses processos.

Tendo em vista, portanto, a centralidade do Estado na criação e operacionalização das interfaces, sugerimos aqui analisar as relações das interfaces a partir das seguintes e interrelacionadas - dimensões: a dimensão da vocação e da autoridade, medida por elementos como a origem, os propósitos e a competência (se são informativas, consultivas e/ou decisórias); e a dimensão do desenho institucional, medida por regras e normativas que ordenam a sua estrutura e funcionamento, além de definir quem estabelece, manipula e/ou controla os mecanismos participativos.

Como vimos, a maioria das interfaces mapeadas não apresenta competência decisória, portanto, de poder de tornar as suas proposições em caráter vinculante. Casos de orçamentos participativos e de conselhos gestores, ou seja, de IP, estariam mais próximos dessa atribuição. Esse reconhecimento é importante tendo em vista que não se pode exigir atribuições para além daquelas para as quais foram criadas. Avaliar uma ouvidoria implica em analisar a sua capacidade de ouvir, processar e responder às demandas dos cidadãos, diferente daqueles conselhos gestores que foram criados para discutir, formular e aprovar políticas públicas a serem levadas a cabo pelo poder governamental. No entanto, em que pesem essas diferenças, um olhar relacional pretende analisar em que medida, por exemplo, os espaços de discussão e de formulação de políticas são alimentados pelos canais institucionais que recolhem diferentes demandas, denúncias e queixas sociais.

Além dessa dimensão da competência das interfaces, ressalta-se a questão da centralidade, e que diz respeito ao lugar político e institucional que a mesma ocupa na 
estrutura governamental, baseada em um poder hierárquico que organiza e distribui os seus diferentes órgãos e setores de acordo com o seu poder de mando e de obediência. Assim, faz diferença se a interface ocupa um lugar mais central ou mais periférico no âmbito da organização estatal, em que pese a relativização da ideia de que os Estados são estruturas centralizadas e controladas hierarquicamente, como desenvolvido por Migdal, Kohli e Shue (1994). De acordo com este estudo, embora a importância das propriedades mais sistêmicas do Estado, o mesmo, mais do que um conjunto de instituições centralizadas e dominadas por uma elite política central, caracteriza-se por múltiplos e diferentes níveis de organização que operam em meios estruturais que sofrem diferentes tipos de influência e de pressão social. Migdal (1994) apresenta quatro níveis de organização estatal, que vão desde as instituições prestadoras de serviço em âmbito local, até o alto comando do poder central. Assim, além das diferentes relações e pressões externas que ocorrem nos diferentes níveis de organização estatal, temos as relações e pressões que se dão no âmbito interno às instituições estatais, sejam elas verticais - entre chefes e subordinados - e horizontais, estabelecidas com outras agências estatais. As diferentes constelações de força nos diferentes níveis vão determinar os resultados políticos, ou a formulação e implementação das políticas estatais.

Nesse sentido, analisar as interfaces implica não apenas em identificar os múltiplos e diferenciados pontos de acesso, como a maneira como a autoridade é exercida, especialmente no que diz respeito à maior ou menor centralização político-administrativa e no grau de autonomia do exercício da autoridade política dado pela multiplicação ou dispersão da autoridade (Amenta et al., 2002). Há também que se considerar, mediante a complexidade do Estado e as suas múltiplas relações com a sociedade, o papel dos agentes estatais. Como salientado por Gomide e Pires (2014), em 
contextos democráticos devemos levar em conta dois componentes das capacidades estatais, quais sejam, o técnico-administrativo e o político. Derivado do conceito weberiano de burocracia, o primeiro contempla as competências dos agentes da burocracia estatal em administrar as políticas. "O segundo, associado à dimensão política, refere-se às habilidades da burocracia do Executivo em expandir os canais de interlocução, negociação com os diversos atores sociais, processando conflitos e prevenindo a captura por interesses específicos" (Gomide e Pires, 2014, p. 20).

O papel das/os burocratas vem sendo objeto de diversos estudos no campo das políticas públicas, visando iluminar a importância desses agentes nos processos de formulação, implementação e avaliação das políticas. Estudos que apontam o caráter da discricionaridade dos burocratas de nível de rua (street level bureaucrats) (Lipsky, 1980), por exemplo, mostram como esses atores tanto podem promover inovações e soluções de problemas emergentes, como podem também reproduzir situações de desigualdade e de subordinação à posições sociais estruturais (Pires, 2019). Assim, seja por deterem conhecimento e informações estratégicas, seja pela maior proximidade com os destinatários das políticas públicas, como é o caso dos burocratas de linha de frente (Secchi, 2010), o fato é que a literatura vem acumulando estudos que apontam para a importância desses agentes nas dinâmicas das políticas públicas, tanto no que diz respeito a sua atuação nas diferentes fases ou ciclos de políticas, quanto na maior ou menor capacidade de interação e articulação institucional e social.

Convém, também, ressaltar para o papel dos governos, com destaque ao perfil dos atores e partidos políticos e no seu maior ou menor envolvimento e compromisso com espaços e dinâmicas participativas e inclusivas. De maneira geral a literatura das IPs tem tratado essa dimensão por meio da variável da vontade política (Sintomer, Herzberg e Rocke, 
2012; Goldfrank, 2006; Avritzer, 2008; Lüchmann, 2014). Um dos principais fundamentos teóricos dessa variável descansa nos pressupostos da vertente que analisa a estrutura de oportunidades políticas (Tarrow, 2009). De acordo com Velásquez (1999), os fatores centrais para a implementação de um controle social de gestão pública pautado na ação coletiva de caráter cooperativo são, entre outros, a estrutura de oportunidades políticas, ou o grau de abertura, vontade e comprometimento do sistema político às demandas de participação. Evitando uma leitura voluntarista que está embutida na ideia de vontade política, vários estudos vêm complexificando essa variável, ao reconhecerem que dinâmicas participativas estão subordinadas não apenas às vontades e humores de governos eleitos, como também estão sujeitas à lógica do sistema político e, por conseguinte, aos interesses e estratégias de outros setores e lideranças partidárias e do legislativo. Como ressaltado por Goldfrank (2006, p. 18), além de atenderem a diferentes interesses políticos em especial ganhar eleições -, os resultados de inovações democráticas, a exemplo dos OPs "no son necesariamente los que originalmente se esperan. Las consecuencias dependen no sólo de la intención de los diseñadores y de los contextos locales, sino de las intenciones y estratégias de otros actores, incluidos los oponentes políticos”.

Assim, importa avaliar as influências tanto institucionais como do jogo político sobre as dinâmicas participativas, com destaque à sua maior ou menor capacidade de estabelecer diálogo e relações com outros canais de participação e de interfaces socioestatais. Por esta via analítica, parece frutífero o regate dos debates mais recentes na teoria deliberativa, em especial do giro sistêmico (Dryzek, 2010) que, na tentativa de se aproximar cada vez mais do "mundo real", resgata a necessidade de focar para o sistema mais amplo no qual os fóruns deliberativos estão inseridos, ampliando as lentes para os diferentes espaços, processos e padrões de 
ação política, e permitindo abrigar diferentes análises sobre as práticas e instituições políticas nas sociedades contemporâneas. De maneira geral, a ideia de sistema deliberativo pretende pensar a democracia como uma ecologia social e institucional, não apenas a partir da compreensão de que diferentes práticas ou instituições comportam diferentes feições e funções - sejam agregativas, competitivas, associativas, participativas, deliberativas, etc. (Warren, 2012), mas da necessidade de ampliar o foco para as características do ambiente político, avaliando o maior ou menor grau de abertura, inclusividade e postura (mais ativa ou passiva) das respectivas estruturas governamentais.

Uma outra dimensão analítica importante diz respeito aos respectivos desenhos ou arranjos institucionais das interfaces socioestatais, ou ao como elas operacionalizam a participação: suas competências e a forma como incorporam os cidadãos e/ou as associações; se instituem assembleias e encontros presenciais ou são dispositivos online; etc. De maneira geral, o desenho institucional define e operacionaliza o conjunto de regras, critérios, espaços, normas, leis, que estabelecem o sentido da participação, impactando, portanto, na sua configuração. O perfil dos participantes é, em boa dose, definido pelos seus respectivos desenhos institucionais, responsáveis, portanto, pela maior ou menor inclusão e pluralização da participação e da representação ali exercida.

De acordo com Smith (2019), uma atenção mais cuidadosa aos desenhos dos espaços participativos surgiu a partir de um conjunto de críticas e suspeitas quanto ao caráter efetivamente democrático das experiências participativas. Entre as críticas, e baseado em diversos estudos, o autor pontua: o reforço do poder social e econômico existente, por meio da inclusão dos atores já politicamente ativos; a falta de competência política dos cidadãos, o que pode tornar a participação um mecanismo que leve a decisões mal informadas; o uso cosmético da participação tendo em vista 
legitimar decisões tomadas em outros lugares; a cooptação do público pelas elites políticas; os riscos dados por expectativas irrealistas quanto aos resultados, ou efeitos concretos da participação; as diferenças nos custos da participação determinadas pelas condições socioeconômicas da população; e os limites dados pela dimensão da escala, cuja extensão tornaria a participação incontrolável (Smith, 2019, p. 5). Diante disso, o desenho institucional ganha centralidade na medida em que está relacionado, de acordo com o autor, com os princípios, objetivos, expectativas, tarefas e mecanismos de recrutamento, decisão, interação, comunicação e accountability. Oportunizar a inclusão de setores mais vulneráveis da população, ampliar a oferta de informação qualificada, diminuir custos da participação, promover transparência, respeitar e incentivar as falas e demandas sociais são, entre outros, aspectos centrais a serem promovidos por um bom desenho institucional.

42 Para além dessas dimensões da participação, os desenhos também são determinantes para pensarmos na questão da articulação entre as interfaces socioestatais, na medida em que podem prever, como são os casos de alguns conselhos gestores e orçamentos participativoss, a ampliação e complexificação de atores e espaços participativos na conformação de sistemas deliberativos, ou de multicanais de engajamento, como visto anteriormente.

Assim, de forma combinada, essas dimensões são consideradas elementos importantes para a compreensão do lugar, da vocação e da inserção - e relação - das interfaces socioestatais. Com efeito, além do mapeamento acerca das origens, dos recursos e dos diferentes propósitos das interfaces, há também que se analisar quem são os atores sociais, burocráticos e político-governamentais, quais são os lugares que ocupam no aparelho governamental, quais são os constrangimentos legais, políticos e burocráticos, como se estruturam os arranjos e os dispositivos institucionais, e qual é a inserção, 
ou a maior ou menor integração ou vinculação, com outros dispositivos e programas de interfaces socioestatais.

\section{Considerações finais}

Tendo em vista o cenário de expansão de instituições e de mecanismos participativos, e que se acentua pelo uso das TIC, o presente trabalho procurou apresentar algumas dimensões analíticas que são consideradas centrais para o avanço nos estudos no campo da participação e da democracia. Ao apresentar alguns dos desdobramentos nos estudos, em especial no Brasil, das IP (conselhos, conferências, orçamentos participativos), o trabalho sugere, frente à proliferação de uma multiplicidade de espaços e mecanismos participativos que visam algum tipo de comunicação e aproximação entre estruturas estatais e cidadãos, a pertinência do conceito de interfaces socioestatais para a identificação desse fenômeno, na medida em que, embora incorpore as IPs, alarga, em muito, as modalidades de interação entre sociedade e Estado, incluindo-se as diferentes ferramentas digitais.

Essa proliferação de interfaces coloca novos desafios no campo de debates da teoria democrática, na medida em que, diferente de se constituírem em sistemas integrados que articulam participação, deliberação e representação, são criadas e funcionam, em boa medida, de forma desarticulada e obedecendo a propósitos e objetivos de acordo com os interesses, estratégias e alianças políticas, e de acordo com os contextos e dinâmicas institucionais. Vimos que esses dispositivos fazem parte de uma perspectiva que, centrada na ideia de governança, trouxe à tona a necessidade de promover o controle social e a responsabilização dos governos, em um momento que foi fortalecido pela agenda internacional ligada ao modelo da NGP ao longo dos anos de 1990. Esse debate encontrou eco na América Latina, em especial pelo papel desenvolvido pelas instituições financeiras internacionais, com destaque para o Banco Mundial. Com efeito, 
tanto no plano nacional como no internacional ampliaram-se os espaços e fluxos de informação entre agências estatais e setores sociais, conformando, em regra, um quadro de fragmentação, dispersão e de superposição institucional. Diante disso, o trabalho buscou apontar para a importância da articulação entre diferentes interfaces, tendo como norte a ideia de que a interação entre os diferentes canais de absorção de demandas sociais possibilita uma dinâmica de funcionamento mais eficiente na produção de diagnósticos que informam os processos de formulação, implementação e avaliação das diferentes políticas públicas, potencializando a gestão mediante a ampliação e pluralização da participação.

Assim, em diálogo com os estudos sobre as instituições participativas, teoria democrática e políticas públicas, sugerimos aqui analisar as relações das interfaces a partir das seguintes dimensões: a dimensão da vocação e da autoridade, medida por elementos como a origem, os propósitos e a competência (se são informativas, consultivas e/ou decisórias); e a dimensão do desenho institucional, medida por regras e normativas que ordenam a sua estrutura e funcionamento, além de definir quem estabelece, manipula e/ou controla os mecanismos participativos. Além do mapeamento acerca das origens, dos recursos e dos diferentes propósitos das interfaces socioestatais, essas dimensões também permitem se identificar os atores - sociais, burocráticos e político-governamentais; os lugares que ocupam no aparelho governamental; os constrangimentos legais, políticos e burocráticos; os arranjos e dispositivos institucionais; e a inserção, ou maior ou menor integração ou vinculação com outros dispositivos e programas de interfaces socioestatais.

\section{Lígia Helena Hahn Lüchmann}

Doutora em Ciências Sociais pela Universidade Estadual de Campinas (Unicamp), professora do Departamento de Sociologia e Ciência Política da Universidade Federal de 
Santa Catarina (UFSC) e coordenadora do Núcleo de Pesquisa em Movimentos Sociais do Programa de Pós-Graduação em Sociologia e Ciência Política da UFSC.

\section{Bibliografia}

ALMEIDA, Carla; TATAGIBA, Luciana. 2012. Os conselhos gestores sob o crivo da política: balanços e perspectivas. Serviço Social Ẽ Sociedade, n. 109 , pp. $68-92$.

ALMEIDA, Carla; CAYRES, Domitila Costa; TATAGIBA, Luciana. 2015. Balanço dos estudos sobre os conselhos de políticas públicas na última década. Lua Nova, n. 105, pp. 55-294.

ALMEIDA, Debora Rezende de. 2014. Pluralização da representação política e legitimidade democrática: lições das instituições participativas no Brasil. Opinião Pública, v. 20, pp. 96-117.

ALMEIDA, Debora Rezende de. 2017. Os desafios da efetividade e o estatuto jurídico da participação: a Política Nacional de Participação Social. Sociedade e Estado, v. 32, pp. 649-680.

AMENTA, Edwin; CAREN, Neal; FETNER, Tina; YOUNG, Michael, P. 2002. Challengers and States: Toward a Political Sociology of Social Movements. Sociological Views on Political Participation in the 21st Century, v. 10 , pp. $47-83$.

AVRITZER, Leonardo. 2008. Instituições participativas e desenho institucional. Opinião Pública, v. 14, pp. 43-64.

AVRITZER, Leonardo; NAVARRO, Zander (org.). 2003. A inovação democrática no Brasil: o orçamento participativo. São Paulo: Cortez.

AVRITZER, Leonardo; SOUZA, Clóvis Henrique Leite de (org.). 2013. Conferências nacionais: atores, dinâmicas participativas e efetividades. Brasília, DF: Ipea.

BORBA, Julian; LÜCHMANN, Lígia Helena Hahn. 2007. Orçamento Participativo: análise das experiências desenvolvidas em Santa Catarina. Florianópolis: Insular.

BORBA, Julian. 2011. Participação política como resultado de instituições participativas: oportunidades políticas e o perfil da participação. In: PIRES, Roberto Rocha (org.). Efetividade das instituições participativas no Brasil: estratégias de avaliação. Brasília, DF: Ipea. v. 7. pp. 65-76.

CAVALCANTE, Pedro; CAMÕES, Marizaura. 2015. Gestão pública no Brasil: as inovações configuram um novo modelo? Paper apresentado no XX Congreso Internacional del Clad, Lima, 10 a 13 de novembro. 
COMPARATO, Bruno Konder. 2016. Ouvidorias públicas como instrumentos para o fortalecimento da democracia participativa e para a valorização da cidadania. In: MENEZES, Ronald do Amaral; CARDOSO, Antonio Semerato Rito (org.). Ouvidoria pública brasileira: reflexões, avanços e desafios. Brasília, DF: Ipea, pp. 43-53.

CORTES, Soraya. Maria Vargas. 2011. As diferentes instituições participativas existentes nos municípios brasileiros. In: PIRES, Roberto Rocha (org.). Efetividade das instituições participativas no Brasil: estratégias de avaliação. Brasília, DF: Ipea, v. 7, pp. 137-150.

CUNILL-GRAU, Nuria. 2014. La intersectorialidad en las nuevas políticas sociales: Un acercamiento analítico-conceptual. Gest. polít. Pública, v. 23, n. 1, pp. 5-46.

DRYZEK, John. 2010. Foundations and Frontiers of Deliberative Governance. New York: Oxford University Press.

FARIA, Cláudia Feres. 2012. Participação e deliberação nas Conferências de Políticas Públicas no Brasil: uma análise comparada. Paper apresentado no $8^{\circ}$ Encontro da Associação Brasileira de Ciência Política, Gramado, 1 a 4 de agosto.

FARIA, Cláudia Feres; SILVA, Viviane Petinelli; LINS, Isabella Lourenço. 2012. Conferências de políticas públicas: um sistema integrado de participação e deliberação? Revista Brasileira de Ciência Política, n. 7, pp. 249-284.

FUNG, Archon. 2006. Varieties of Participation in Complex Governance. Public Administration Review, v. 66, n. 1, pp. 66-75.

FUNG, Archon. 2015. Putting the Public Back into Governance: The Challenges of Citizen Participation and its Future. Public Administration Review, v. 75, n. 4, pp. 513-522.

GOLDFRANK, Benjamin. 2006. Los procesos de 'presupuesto participativo' en América Latina: éxito, fracaso y cambio. Revista de Ciencia Política, v. 26, n. 2, pp. 3-28.

GOMIDE, Alexandre de Ávila; PIRES, Roberto Rocha. 2014. Capacidades Estatais e democracia: arranjos institucionais de politicas públicas. Brasília, DF: Ipea.

GURZA LAVALLE, Adrián; CASTELLO, Graziela. 2008. Sociedade civil, representação e a dupla face da accountability: Cidade do México e São Paulo. Caderno CRH, v. 21, n. 52, pp. 67-86.

GURZA LAVALLE, Adrián; HOUTZAGER, Peter; CASTELLO, Graziela. 2006. Democracia, pluralização da representação política e sociedade civil. Lua Nova, n. 67, pp. 49-103. 
GURZA LAVALLE, Adrián; ISUNZA VERA, Ernesto. 2010. Precisiones conceptuales para el debate contemporáneo sobre la innovación democrática: participación, controles sociales y representación. In: ISUNZA VERA, Ernesto; GURZA LAVALLE, Adrián (org.). La innovación democrática en América Latina: tramas y nudos de la representación, la participación y el control social. Ciudad del México, DF: Ciesa. pp. 19-82.

GURZA LAVALLE, Adrián; SZWAKO, José. 2014. Origens da Política Nacional de Participação Social: entrevista com Pedro Pontual. Novos Estudos CEBRAP, v. 99, pp. 91-104.

HENDRIKS, Carolyn. 2006. Integrated deliberation: reconciling civil society's dual role in deliberative democracy. Political Studies, v. 54, n. 3, pp. 486-508.

HEVIA, Felipe; ISUNZA VERA, Ernesto. 2010. La perspectiva de interfaz aplicada a las relaciones sociedad civil-Estado en México. In: OLVERA, Alberto (coord.). La democratización frustrada. México: Ciesas. pp. 59-128.

ISUNZA VERA, Ernesto; GURZA LAVALLE, Adrián. 2012. Arquitetura da participação e controles democráticos no Brasil e no México. Novos estudos CEBRAP, n. 92, pp. 105-121.

ISUNZA VERA Ernesto; GURZA LAVALLE, Adrián (org.). 2010. La innovación democrática en América Latina: tramas y nudos de la representación, la participación y el control social. Ciudade del México, DF: Ciesas.

ISUNZA VERA, Ernesto; HEVIA, Felipe. 2006. Relaciones sociedad civil-Estado en México: Un ensayo de interpretación. Ciudad del México, DF: Ciesas. Disponível em: https://bit.ly/3b9pjYX. Acesso em: 9 abr. 2020.

LIPSKY, Michael. 1980. Street-level Bureaucracy. New York: Russell Sage Foundation.

LONG, Norman. 1999. The Multiple Optic of Interface Analysis. Paris: Unesco. (Background Paper on Interface Analysis). Disponível em: https://bit.ly/3a08X4i. Acesso em: 9 abr. 2020.

LOPEZ, Feliz Garcia; PIRES, Roberto Rocha. 2010. Instituições participativas e políticas públicas no Brasil: características e evolução nas últimas duas décadas. In: CARDOSO Jr., José Celso. Brasil em Desenvolvimento: Estado, Planejamento e Políticas Públicas. Brasília, DF: Ipea. pp. 565-585.

LOTTA, Gabriela; OLIVEIRA, Vanessa; CAVALCANTE, Pedro. 2016.

Do insulamento burocrático à governança democrática:

Transformações institucionais e a burocracia no Brasil. Paper apresentado no X Encontro da Associação Brasileira de Ciência Política, Belo Horizonte, 30 de agosto a 2 de setembro. 
LÜCHMANN, Lígia Helena Hahn. 2007. A representação no interior das experiências de participação. Lua Nova, n. 70, pp. 139-170.

LÜCHMANN, Lígia Helena Hahn. 2014. 25 anos de Orçamento Participativo: algumas reflexões analíticas. Política $\mathcal{E}^{2}$ Sociedade, v. 13, pp. 167-197.

LÜCHMANN, Lígia Helena Hahn; ABRAO, Rachel; KIELING, Matheus. 2019. Interfaces das interfaces socioestatais: um estudo sobre as ouvidorias. E-Legis, v. 28, pp. 145-176.

MEDAGLIA, Rony. 2012. eParticipation research: moving characterization forward (2006-2011). Government Information Quarterly, v. 29, n. 3, pp. 346-360.

MIGDAL Joel Samuel. 1994. An introduction. In: MIGDAL, Joel Samuel; KOHLI, Atul; SHUE, Vivienne (org.). State power and social forces: domination and transformation in the Third World. Cambridge: University Press. pp. 1-4.

PIRES, Roberto Rocha (org.). 2011. Efetividade das instituições participativas no Brasil: estratégias de avaliação. Brasília, DF: Ipea. v. 7.

PIRES, Roberto Rocha (org). 2019. Implementando desigualdades: reprodução de desigualdades na implementação de políticas públicas. Rio de Janeiro: Ipea.

PIRES, Roberto Rocha; VAZ, Alexander C. N. 2014. Para além da participação: Interfaces socioestatais no governo federal. Lua Nova, n. 93, pp. 61-91.

ROBERTS, Bryan. 2001. Las nuevas políticas sociales en América Latina y el desarrollo de ciudadania: una perspectiva de interfaz. Documento elaborado para o Taller Agencia, Conocimiento y Poder: nuevas direcciones, Wageningen, 14 e 15 de dezembro.

SECCHI, Leonardo. 2010. Políticas públicas: conceitos, esquemas de análise, casos práticos. São Paulo: Cengage Learning.

SILVA, Fabio de Sá e; LOPEZ, Felix Garcia; PIRES, Roberto Rocha (org.). 2010. Estado, instituições e democracia: democracia. Brasília, DF: Ipea.

SILVA, Marcelo Kunrath. 2011. Dos casos aos tipos: notas para uma apreensão das variações qualitativas na avaliação das instituições participativas. In: PIRES, Roberto Rocha (org.). Efetividade das instituições participativas no Brasil: estratégias de avaliação. Brasília, DF: Ipea. v. 7. pp. 233-246.

SILVA, Sivaldo Pereira. 2005. Graus de participação democrática no uso da internet pelos governos das capitais brasileiras. Opinião Pública, v. 11, n. 2, pp. 450-468.

SINTOMER, Yves; HERZBERG, Carsten; RÖCKE, Anja. 2012. Modelos transnacionais de participação cidadã: o caso do orçamento participativo. Sociologias, v. 14, n. 30, pp. 70-116. 
SMITH, Graham Norman. 2019. Design Matters: CBNRM and Democratic Innovation. Washington DC, World Bank.

SORENSEN, Eva; TORFING, Jacob. 2007. Theoretical Approaches to Governance Network Dynamics. In: SORENSEN, Eva; TORFING, Jacob. Theories of Democratic Network Governance. New York: Palgrave Macmillan. p. 25-42.

SPADA, Paolo; ALLEGRETTI, Giovanni. 2017. Integrating Multiple Channels of Engagement in Democratic Innovations: Opportunities and Challenges. In: ADRIA, Marco; MAO, Yuping. Handbook of Research on Citizen Engagement and Public Participation in the Era of New Media. EUA, IGI Global. pp. 20-37.

TARROW, Sidney. 2009. O poder em movimento: movimentos sociais e confronto político. Petrópolis: Vozes.

TEIXEIRA, Ana Cláudia.; SOUZA, Clóvis Henrique Leite; LIMA, Paula Pompeu Fiuza. 2012. Arquitetura da Participação no Brasil: uma leitura das representações políticas em espaços participativos nacionais. Brasília, DF: Ipea. (Texto para Discussão n. 1735).

VELÁSQUEZ, Fábio. 1999. A Observadoria cidadã na Colômbia - em busca de novas relações entre o Estado e a sociedade civil. In: BRESSER-PEREIRA, Luís Carlos.; GRAU, Núria Cunill (org.). O Público não-estatal na reforma do estado. Rio de Janeiro: FGV. pp. 257-291.

WAMPLER, Brian. 2011. Instituições participativas como "enxertos" na estrutura do estado: a importância de contextos, atores e suas estratégias. In: PIRES, Roberto Rocha (org.). Efetividade das instituições participativas no Brasil: estratégias de avaliação. Brasília, DF: Ipea. v. 7. pp. 151-158.

WARREN, Mark. 2012. When, where and why do we need deliberation, voting, and other means of organizing democracy? A problem-based approach to democratic systems. Paper apresentado no Annual Meeting of the American Political Science Association, 30 de agosto a 2 de setembro. 


\section{INTERFACES SOCIOESTATAIS E INSTITUIÇÕES PARTICIPATIVAS: DIMENSÕES ANALÍTICAS}

\section{LÍGIA HELENA HAHN LÜCHMANN}

Resumo: Mobilizando os conceitos de interfaces socioestatais e de instituições participativas, o trabalho visa apresentar algumas dimensões analíticas para o avanço dos estudos voltados à compreensão da vocação e do lugar ocupado por estas no interior do aparelho estatal, com o foco na sua inserção, ou maior ou menor integração, com outros dispositivos e programas de interfaces socioestatais. Sugerimos aqui analisar as relações das interfaces a partir das seguintes dimensões: a dimensão da vocação e da autoridade, medida por elementos como a origem, os propósitos e a competência (se são informativas, consultivas e/ou decisórias); e a dimensão do desenho institucional, medida por regras e normativas que ordenam a sua estrutura e funcionamento.

Palavras-chave: Interfaces Socioestatais; Instituições Participativas; Democracia; Participação; Governança.

\section{SOCIO-STATE INTERFACES AND PARTICIPATIVE INSTITUTIONS: ANALYTICAL DIMENSIONS}

Abstract: Mobilizing the concepts of socio-state interfaces and participative institutions, the present work presents some analytical dimensions for the advancement in studies aimed at understanding the vocation and the place that these interfaces occupy in the interior of the state apparatus, with the focus on its insertion, or more or less integration, with other socio-state interfaces. We suggest here to analyze the interface relationships from the following dimensions: the dimension of vocation and authority, measured by elements such as origin, purpose and competence (if they are informative, advisory and / or decision-making); and 
Resumos $\mid$ Abstracts

the dimension of institutional design, measured by rules and regulations that order its structure and functioning.

Keywords: Social-State Interfaces; Participative Institutions; Democracy; Participation; Governance.

Recebido: 18/02/2019 Aprovado: 29/03/2020 